\title{
Extraction and Hydrophobic Modification of Cotton Stalk Bark Fiber
}

\author{
Ya-Yu Li, Guang-Ming Du, Xin-Jie Feng, Ya-Wei Mu, and De-Qiang Li \\ College of Chemical Engineering, Xinjiang Agricultural University, Urumqi, Xinjiang 830052, China \\ Correspondence should be addressed to Ya-Yu Li; 835084132@qq.com
}

Received 28 March 2016; Accepted 28 April 2016

Academic Editor: Jun Yang

Copyright (C) 2016 Ya-Yu Li et al. This is an open access article distributed under the Creative Commons Attribution License, which permits unrestricted use, distribution, and reproduction in any medium, provided the original work is properly cited.

Cotton stalk bark fiber (CSBF) was extracted at high temperature and under high pressure, under the condition of the alkali content of $11 \mathrm{wt} \%$. Experimental results proved that the extraction yield of CSBF was $27.3 \mathrm{wt} \%$, and the residual alkali concentration was $2.1 \mathrm{wt} \%$. Then five kinds of modifiers including methyl methacrylate (MMA), MMA plus initiator, epoxy propane, copper ethanolamine, and silane coupling agent were chosen to modify the surface of CSBF. It was found by measuring water retention value (WRV) that these five kinds of modifiers were all effective and the silane coupling agent was best modifier among all. The optimal modifying conditions of silane coupling agent were obtained: modifier concentration was $5 \%$, the mixing temperature was $20^{\circ} \mathrm{C}$, the mixing time was $1 \mathrm{~h}$, and vacuum drying time was $1 \mathrm{~h}$. Under the optimal condition, the WRV of the modified CSBF was $89 \%$. It is expected that these modified CSBF may be a filler with strengthening effect in wood plastic composites (WPC) fields.

\section{Introduction}

The plastics substitutes have been receiving more attention due to its applications in solving the problem of white pollution $[1,2]$. Among the plastics substitutes, renewable biomass material from agricultural by-product such as cotton stalk is one of the considerable candidates [2]. It was reported that adding wood fiber into plastics to produce wood plastic composites (WPC) could improve the mechanical properties of plastics such as tensile strength, reduce the dosage of plastic materials, and decrease the cost [3].

Cotton is an important human subsistence and industrial raw material. Xinjiang is the largest province of commercial cotton planted in China. In 2013, the cotton output in Xinjiang reached 3.4 million tons, occupying more than $58 \mathrm{wt} \%$ of that in China. Akdeniz et al. [4] reported that the cotton stalk was equivalent to three times the weight of the cotton fiber. Nowadays, the cotton stalk after harvest is mostly taken back into farmland or directly burned as fuel in low utilization value. When the cotton stalk is smashed and scattered into soil of the same field for several years, it is prone to induce cotton diseases on this field, which is a big problem affecting cotton growth. Therefore, development of simple and low cost methods for the high value-added biomaterials produced by cotton stalk is of great importance for broadening and improving its applications [5]. It was reported that $26 \mathrm{wt} \%$ of cotton stalk was bark [6], which was composed of $41 \mathrm{wt} \%$ of cellulose, $21 \mathrm{wt} \%$ of hemicellulose, $18 \mathrm{wt} \%$ of lignin, $5 \mathrm{wt} \%$ of pectin, $10 \mathrm{wt} \%$ of water-soluble matter, and $4 \mathrm{wt} \%$ of wax [7]. Dong et al. [8] reported that the fibers extracted from cotton stalk bark (CSB) displayed tensile properties close to cotton fibers. Young' modulus of cellulose of crystal state was reported as $250 \mathrm{Gpa}$, which was three times that of E-glass [9]. In all, the cellulose fiber extracted from cotton stalk displayed potential applications in structural materials.

Generally, the cotton stalk bark fiber (CSBF) is obtained through degumming under the condition of alkali solution at normal pressure [5-7]. In addition, steam explosion was also reported to extract the CSBF $[8,10,11]$. CSBF has strong water imbibition property due to its hydroxyl groups of cellulose, leading to a short service life of WPC in the natural environment. In recent years, rapid progress has been made in the modification of plant fibers including silane treatment [12], alkaline treatment [6], copper amine [13], acetylation [14], maleated coupling [15], and enzyme treatment [16]. For example, Park et al. [17] found that jute fiber treated by silane 


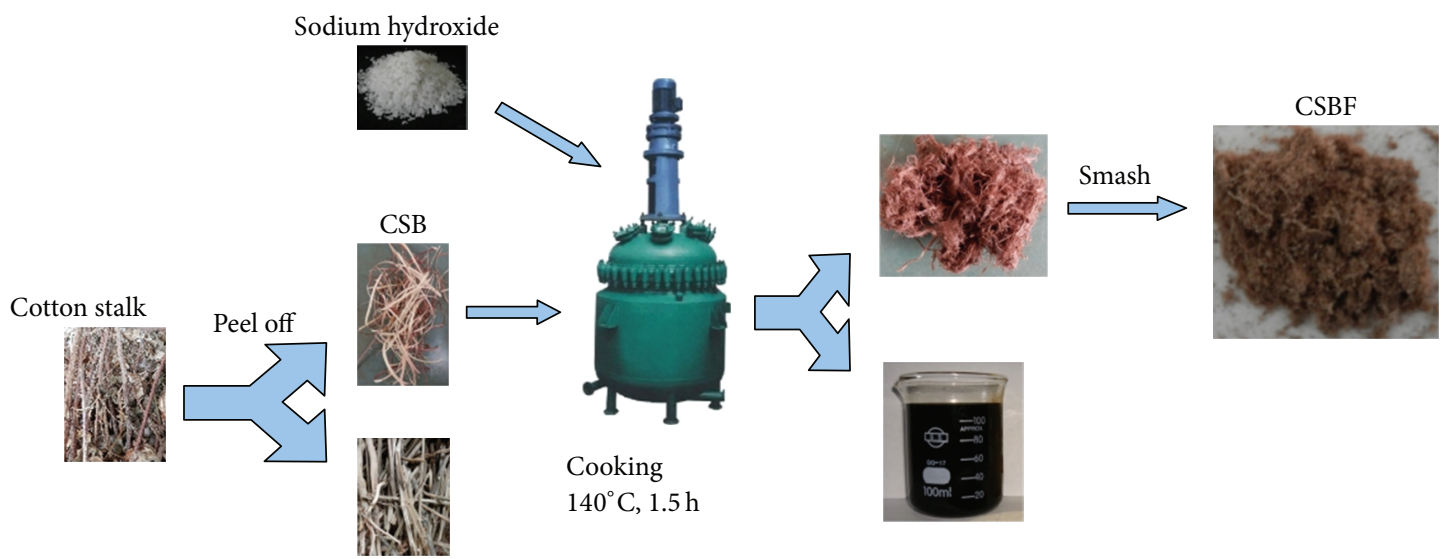

FIGURE 1: The extraction process of cotton stalk bark fiber.

made the surface coherence of fiber and polypropylene tight. Islam et al. [18] reported that the modulus of elasticity (MOE) and compressive modulus of wood were significantly boosted after treatment with MMA (methyl methacrylate)/PVA (polyvinyl alcohol), indicating improvement of mechanical properties of the wood samples. Hydroxyl in cellulose and guaiacol in lignin could react with epoxypropane to form ether [19], which reduced the hydrophilicity of cellulose or lignin. Jiang and Kamdem [13] reported an increase up to around $45 \%$ in unnotched impact strength using $0.2 \mathrm{wt} \%$ copper amine-treated WF at the $60 \mathrm{wt} \%$ PVC loading level, compared with untreated wood flour. In all, the five modifiers including MMA, MMA plus initiator, epoxypropane, copper ethanolamine, and silane coupling agent were effective and low cost. However, as far as we know, the modification of CSBF using the five modifiers MMA, MMA plus initiator, epoxypropane, copper ethanolamine, and silane coupling agent has not been reported yet. Comparative study about the validity of these five modifiers will help understand the modification mechanism on CSBF.

Herein, CSBF was extracted by using the alkali method under high temperature and high pressure. Then, five modifiers including MMA, MMA plus initiator, epoxypropane, copper ethanolamine, and silane coupling agent were chosen to process CSBF, respectively. Moreover, the influences of the modification conditions were also investigated in detail. It is believed that these modified CSBF may be a potential application in wood plastic composites fields.

\section{Material and Methods}

2.1. Materials. Cotton stalks was taken from 314 Tuan, Shihezi, in October 2014. Sodium hydroxide, anhydrous ethanol, ethanol amine, alkali type copper carbonate, potassium persulfate, methyl methacrylate, epoxypropane, and silane coupling agent are all analytically pure, used as purchased from Sinopharm Chemical Reagent Co., Ltd.

2.2. Extraction of CSBF. In a typical experiment, cotton stalk bark (CSB) was peeled off first. Then the CSB was put into a kettle at $140^{\circ} \mathrm{C}$ for $1.5 \mathrm{~h}$ with $\mathrm{NaOH}$ under vigorous stirring
(Figure 1). The weight of $\mathrm{NaOH}$ was $11 \%$ in comparison with that of CSB. The product was separated from the solution by centrifugation, dried in air at $50^{\circ} \mathrm{C}$, and smashed for further modification process.

Determination of Residual Alkali Content in Black Liquid. $10 \mathrm{~mL}$ black liquid and $10 \mathrm{~mL} 6 \mathrm{wt} \%$ barium chloride were pipetted to $100 \mathrm{~mL}$ volumetric flask and then lignin was completely precipitated. The solution was diluted with distilled water to the scale line, shaken well, and let stand. Upper clear liquid in the volumetric flask was pipetted into conical flask. Using phenolphthalein as indicator and hydrochloric acid as standard solution, titration was done until the solution color changed from light yellow to red at the end point. Alkaline residue was calculated according to the dosage of hydrochloric acid solution.

2.3. Modification of CSBF. In a typical procedure, $0.5 \mathrm{~g}$ dry CSBF and $1 \mathrm{~g}$ modifier (MMA, MMA plus initiator, epoxy propane, copper ethanolamine, and silane coupling agent) were added into the mixture of $8.5 \mathrm{~g}$ ethanol and $0.5 \mathrm{~g}$ water. The mixture was stirred for $1.5 \mathrm{~h}$ at room temperature. After that, the product was filtered and transferred to a vacuum oven at $105^{\circ} \mathrm{C}$ for $2 \mathrm{~h}$. In the process, the condensation dehydration, grafting, and polymerization reaction occurred. Finally, the modified CSBF was washed for 5 times with mixture of ethanol and water and dried in wind drying oven until constant weight.

2.4. Water Retention Value. Water retention value (WRV) was analyzed as previously reported by Raj et al. [20]. In a typical procedure, $2 \mathrm{~g}$ absorbent paper was placed at the bottom of the centrifuge tube $(3 \mathrm{~mL})$, and copper net of 100 meshes was placed on the absorbent paper. At the same time, a filter paper was cut and folded into a cone shape and filled with approximately $0.15 \mathrm{~g}$ CSBF, which had been immersed into deionized water for $2 \mathrm{~h}$. Subsequently, the cone paper was placed on the copper net. In the end, the centrifugal tube was closed and the determination component of WRV was ready. After centrifugation, the weight of wet CSBF was 
TABLE 1: The WRV of various fibers modified by different reagents.

\begin{tabular}{lccccccc}
\hline Code name & A & B & C & D & E & F \\
\hline Fibers & CSB & CSBF & $\begin{array}{c}\text { CSBF modified } \\
\text { by MMA }\end{array}$ & $\begin{array}{c}\text { CSBF modified by } \\
\text { initiator + MMA }\end{array}$ & $\begin{array}{c}\text { CSBF modified } \\
\text { by epoxy } \\
\text { propane }\end{array}$ & $\begin{array}{c}\text { CSBF modified by } \\
\text { copper } \\
\text { ethanolamine }\end{array}$ CSBF modified \\
by silane \\
coupling agent
\end{tabular}

determined as $m_{1}$. Afterwards, the wet CSBF was dried in an air-circulating oven and its weight was determined as $m_{2}$. The WRV is calculated by the formula below:

$$
\mathrm{WRV}=\frac{m_{1}-m_{2}}{m_{2}} \times 100 \%
$$

2.5. Fourier Transform Infrared (FT-IR) Spectroscopy. Fourier transform infrared (FT-IR) spectroscopy was carried out on an FT-IR spectrophotometer (EQUINOX55) using the $\mathrm{KBr}$ disk method. Before testing, the CSBF was dried at $105^{\circ} \mathrm{C}$ for $24 \mathrm{~h}$ and the testing samples were prepared with the mass ratio between $\mathrm{CSBF}$ and dried $\mathrm{KBr}$ of $1: 300$. Thirty-two scans were taken for each sample and data were recorded from the range $4000-400 \mathrm{~cm}^{-1}$ at a resolution of $4 \mathrm{~cm}^{-1}$ in the transmission mode.

\section{Result and Discussion}

\subsection{Yield of CSBF Extraction. Consider}

$$
\text { Extraction yield }=\frac{m(\mathrm{CSBF})}{m(\mathrm{CSB})} \times 100 \%
$$

The CSBF makes up $26 \mathrm{wt} \%$ of the mass of CSB [6]. In this work, the extraction yield of CSBF was $27.3 \%$, implying the approximately complete removal of lignin, hemicellulose, pectin, and other impurities.

The CSB was cooked under high temperature and high pressure, and the alkali mass was set $11 \%$ in relation to that of CSB (the alkali aqueous solution was $3.1 \mathrm{~g} / \mathrm{L}$ ). After cooking, the alkali residue was $2.1 \%$ (aqueous solution concentration was $0.61 \mathrm{~g} / \mathrm{L}$ ). Alkali concentration dropped substantially. The reaction was more fully accomplished among alkali and lignin, hemicellulose, pectin, and so forth. Previous literature needed $\mathrm{NaOH}$ solution with concentration of about $30 \mathrm{~g} / \mathrm{L}$ at normal temperature [21]. In this work, the similar result was obtained at high temperature with the concentration of $\mathrm{NaOH}$ solution of only $3.1 \mathrm{~g} / \mathrm{L}$. These results showed that the amount of $\mathrm{NaOH}$ dosage was greatly decreased, which reduced the amount of alkali waste emission and disposal.

3.2. Water Retention Value. One of the simple methods to study the hydrophilicity of the cellulose fiber surface is to measure the water retention value (WRV). Under the premise of same fiber fineness, WRV can reflect the fiber hydrophilic property; that is, the fiber with high value of WRV shows being more hydrophilic. The WRV of various fibers were shown in Table 1 . The WRV of CSB was $127 \%$. As for CSBF, its WRV dramatically increases to $322 \%$.
In this work, the lignin and other weak hydrophilic substance in cotton stalk were almost removed by alkali cooking. The residue was cellulose, which displayed strong hydrophilicity.

When the CSBF was modified by five modifiers including MMA, the MMA plus initiator, epoxypropane, copper ethanolamine, and silane coupling agent, their WRV are $175 \%, 148 \%, 126 \%, 125 \%$, and $122 \%$, respectively. These values obviously decrease, compared with that of CSBF. The hydrophobicity of CSBF was greatly improved after being modified by those five kinds of reagents. The enhancement of hydrophobicity could be achieved by the addition of initiator to MMA (samples C and D), since the initiator could enhance the MMA grafting efficiency on the surface of CSBF. All the three latter modifiers in Table 1 including epoxypropane, copper ethanolamine, and silane coupling agent displayed good hydrophobicity effects. In the previous literature [12, $13,19]$, the mechanisms by these three modifiers had been explained. We try to explain the interaction mechanisms between silanes and natural fibers [12]. First of all, the silane monomers are hydrolyzed in the presence of water. Then, during the hydrolysis process, the concomitant condensation of silanols (aging) also takes place. After that, the reactive silanol monomers or oligomers are physically adsorbed to hydroxyl groups of natural fibers. Finally, under heating conditions, the hydrogen bonds between the silanols and the hydroxyl groups of fibers could be converted into the covalent bonds and liberating water.

3.3. FT-IR Spectra. The FT-IR spectrum of CSB was shown in Figure 2(a). The band at $3424 \mathrm{~cm}^{-1}$ is $\mathrm{O}-\mathrm{H}$ stretching vibration peak. The band at $2927 \mathrm{~cm}^{-1}$ is $\mathrm{C}-\mathrm{H}$ peak. The band at $1739 \mathrm{~cm}^{-1}$ is the absorption of carbonyl stretching of ester or carboxyl groups in hemicelluloses. The band at $1633 \mathrm{~cm}^{-1}$ is the bending vibration peak of water. The band at $1515 \mathrm{~cm}^{-1}$ is the absorption of aromatic skeletal vibration in lignin. The band at $1250 \mathrm{~cm}^{-1}$ is the absorption of stretching vibrations of carbonyl groups in hemicelluloses. The band at $1047 \mathrm{~cm}^{-1}$ is a strong peak of C-O stretching vibration linked to hydroxyl. As for the FT-IR spectrum of CSBF (Figure 2(b)), most of the peaks are similar to those in Figure 2(a). However, the peaks at $1739 \mathrm{~cm}^{-1}, 1515 \mathrm{~cm}^{-1}$, and $1250 \mathrm{~cm}^{-1}$ are weaker than those in Figure 2(a), indicating the removal of hemicellulose and lignin after the extraction process. The band intensity at $891 \mathrm{~cm}^{-1}$ is obviously increased, suggesting the increase of cellulose content. The band at $891 \mathrm{~cm}^{-1}$ was assigned to $\beta-1,4$ glycosidic bond characteristic absorption between the monosaccharides of cellulose $[7,8,22]$. 
TABLE 2: The factor-level design.

\begin{tabular}{lcccc}
\hline Levels & & & Factors \\
& $A$ stirring temperature $\left({ }^{\circ} \mathrm{C}\right)$ & $B$ stirring time $(\mathrm{h})$ & C vacuum drying time $(\mathrm{h})$ & $\mathrm{D}$ concentration of modifier \\
\hline 1 & 0 & 1.5 & 2 & $10 \%$ \\
2 & 20 & 1 & $3 \%$ & $5 \%$ \\
3 & 40 & 2 & 3 & $1 \%$ \\
\hline
\end{tabular}

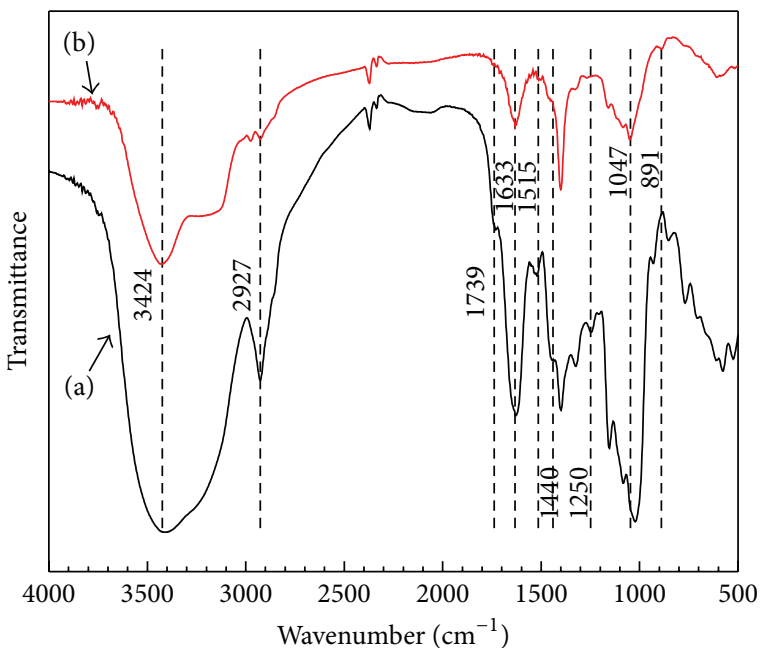

FIGURE 2: FT-IR spectra of (a) raw cotton stalk bark and (b) the extracted cotton stalk bark fiber.

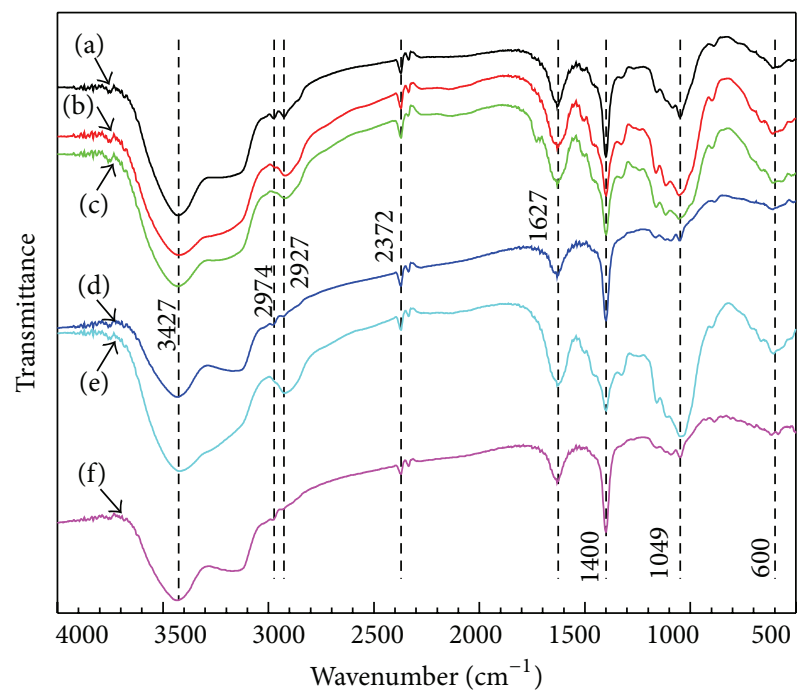

FIGURE 3: FT-IR spectra of CSBF and 5 kinds of modified fibers: (a) CSBF; (b) CSBF modified by MMA; (c) CSBF modified by initiator + MMA; (d) CSBF modified by epoxypropane; (e) CSBF modified by copper ethanolamine; (f) CSBF modified by silane coupling agent.

Figure 3 displayed the FT-IR spectra of raw and modified CSBF. The band at $3427 \mathrm{~cm}^{-1}$ is $\mathrm{O}-\mathrm{H}$ stretching vibration peak. The bands at $2974 \mathrm{~cm}^{-1}$ and $2927 \mathrm{~cm}^{-1}$ are C-H peaks. The band at $2372 \mathrm{~cm}^{-1}$ is the triple bond or cumulative double bond stretching vibration peak. The band at $1627 \mathrm{~cm}^{-1}$ is
TABLE 3: The results of optimization experiment.

\begin{tabular}{lccccc}
\hline \multirow{2}{*}{ Test number } & \multicolumn{4}{c}{ Factors } & Result \\
& $A$ & $B$ & $C$ & $D$ & WRV \\
\hline 1 & 1 & 1 & 1 & 1 & $113 \%$ \\
2 & 1 & 2 & 2 & 2 & $90 \%$ \\
3 & 1 & 3 & 3 & 3 & $108 \%$ \\
4 & 2 & 1 & 2 & 3 & $108 \%$ \\
5 & 2 & 2 & 3 & 1 & $102 \%$ \\
6 & 2 & 3 & 1 & 2 & $101 \%$ \\
7 & 3 & 1 & 3 & 2 & $103 \%$ \\
8 & 3 & 2 & 1 & 3 & $99 \%$ \\
9 & 3 & 3 & 2 & 1 & $109 \%$ \\
\hline
\end{tabular}

the bending vibration peak of water. The band at $1400 \mathrm{~cm}^{-1}$ is a strong peak. The band at $1049 \mathrm{~cm}^{-1}$ is a strong peak of C-O stretching vibration linked to hydroxyl. The band at $600 \mathrm{~cm}^{-1}$ is the fingerprint absorption of hexatomic ring in carbohydrate. It is found that there is little difference among these FT-IR spectra, which is the consequence of the little changing of functional groups induced by surface modification [23].

3.4. Optimization of Experiment Condition. After a theoretical analysis, one can determine that all the stirring temperature, stirring time, vacuum drying time, and the concentration of modifier had an important effect on the modification of CSBF. Therefore, the influences of these four factors were marked as $A, B, C$, and $D$, and every factor was investigated in three levels marked as levels 1,2 , and 3 , as shown in Table 2. For example, the stirring temperature was set as 0,20 , and $40^{\circ} \mathrm{C}$ for different tests, and these three levels were marked as levels 1,2 , and 3 , respectively.

The experiment result and analysis are shown in Tables 3 and 4, respectively. The influence order of the four factors was followed as $B>C>D>A$. Because the influences of both $A$ and $C$ factors were extremely small, they could be negligible factors and the levels of these two factors were determined as follows: stirring temperature was room temperature and vacuum drying time was $1 \mathrm{~h}$. The optimal levels of $B$ and $D$ factors were both level 2; that is, the mixing time was $1 \mathrm{~h}$, and modifier concentration was $5 \%$. At last, the optimum conditions were determined as $A 2, B 2, C 2$, and $D 2$. Under the optimal experiment conditions, the WRV of the modified CSBF was $89 \%$. This result verified that the above combination is the optimal conditions: the stirring temperature was $20^{\circ} \mathrm{C}$, stirring time was $1 \mathrm{~h}$, vacuum drying time was $1 \mathrm{~h}$, and modifier concentration was $5 \%$. 
TABLE 4: The analysis of optimization experiment.

\begin{tabular}{lcccc}
\hline \multirow{2}{*}{ Kalue } & \multicolumn{4}{c}{ Factors } \\
& $A$ & $B$ & $C$ & $D$ \\
\hline$K 1$ & $311 \%$ & $324 \%$ & $312 \%$ & $324 \%$ \\
$K 2$ & $311 \%$ & $291 \%$ & $307 \%$ & $295 \%$ \\
$K 3$ & $311 \%$ & $318 \%$ & $313 \%$ & $314 \%$ \\
$k 1$ & $104 \%$ & $108 \%$ & $104 \%$ & $108 \%$ \\
$k 2$ & $104 \%$ & $97 \%$ & $103 \%$ & $98 \%$ \\
$k 3$ & $104 \%$ & $106 \%$ & $104 \%$ & $105 \%$ \\
Spannweite & 0 & $11.1 \%$ & $1.9 \%$ & $9.8 \%$ \\
Optimum & $A 2$ & $B 2$ & $C 2$ & $D 2$ \\
\hline
\end{tabular}

\section{Conclusions}

In summary, CSBF was extracted under the low concentration of alkali by an environmentally-friendly extraction method using high temperature and high pressure reaction kettle. Five modifiers including MMA, the MMA plus initiator, epoxypropane, copper ethanolamine, and silane coupling agent were used to modify CSBF. It was found that all the five modifiers could raise the hydrophobic property of CSBF. The as-modified CSBF by silane coupling agent displayed excellent hydrophobic property among five kinds of modifiers. The optimal condition of silane coupling agent on CSBF was studied in detail. It was found that the WRV of asmodified CSBF was $89 \%$ at $20^{\circ} \mathrm{C}$ with stirring time of $1 \mathrm{~h}$ and vacuum drying time of $1 \mathrm{~h}$ using modifier concentration of $5 \%$. It is believed that these modified CSBF may be a potential application in WPC fields.

\section{Competing Interests}

The authors declare that they have no competing interests.

\section{Acknowledgments}

The authors are indebted to the Xinjiang Agriculture University for financial support by Projects of the ProphaseSustentation Foundation (Grant no. XJAU201414).

\section{References}

[1] Z. Fei, S. Huang, J. Yin, F. Xu, and Y. Zhang, "Preparation and characterization of bio-based degradable plastic films composed of cellulose acetate and starch acetate," Journal of Polymers \& the Environment, vol. 23, no. 3, pp. 383-391, 2015.

[2] F. Razza, F. D. Innocenti, A. Dobon, C. Aliaga, C. Sanchez, and M. Hortal, "Environmental profile of a bio-based and biodegradable foamed packaging prototype in comparison with the current benchmark," Journal of Cleaner Production, vol. 102, pp. 493-500, 2015.

[3] O. Faruk, A. K. Bledzki, H.-P. Fink, and M. Sain, "Biocomposites reinforced with natural fibers: 2000-2010," Progress in Polymer Science, vol. 37, no. 11, pp. 1552-1596, 2012.

[4] R. C. Akdeniz, M. Acaroglu, and A. Hepbasli, "Cotton stalk as a potential energy source," Energy Sources, vol. 26, no. 1, pp. 6575, 2004.
[5] N. Reddy and Y. Yang, "Properties and potential applications of natural cellulose fibers from the bark of cotton stalks," Bioresource Technology, vol. 100, no. 14, pp. 3563-3569, 2009.

[6] L. Li, J. Sun, and G. Jia, "Properties of natural cotton stalk bark fiber under alkali treating," Journal of Applied Polymer Science, vol. 125, no. 2, pp. E534-E539, 2012.

[7] L. Zhou, J.-Z. Shao, X.-X. Feng, and J.-Y. Chen, "Effect of hightemperature degumming on the constituents and structure of cotton stalk bark fibers," Journal of Applied Polymer Science, vol. 125, no. 2, pp. E573-E579, 2012.

[8] Z. Dong, X. L. Hou, F. F. Sun, L. Zhang, and Y. Q. Yang, “Textile grade long natural cellulose fibers from bark of cotton stalks using steam explosion as a pretreatment," Cellulose, vol. 21, pp. 3851-3860, 2014.

[9] A. K. Bledzki and J. Gassan, "Composites reinforced with cellulose based fibres," Progress in Polymer Science, vol. 24, no. 2, pp. 221-274, 1999.

[10] F. M. V. Oliveira, I. O. Pinheiro, A. M. Souto-Maior, C. Martin, A. R. Gonçalves, and G. J. M. Rocha, "Industrial-scale steam explosion pretreatment of sugarcane straw for enzymatic hydrolysis of cellulose for production of second generation ethanol and value-added products," Bioresource Technology, vol. 130, pp. 168-173, 2013.

[11] X. Hou, F. Sun, L. Zhang, J. Luo, D. Lu, and Y. Yang, "Chemicalfree extraction of cotton stalk bark fibers by steam flash explosion," BioResources, vol. 9, no. 4, pp. 6950-6967, 2014.

[12] Y. Xie, C. A. S. Hill, Z. Xiao, H. Militz, and C. Mai, "Silane coupling agents used for natural fiber/polymer composites: a review," Composites Part A: Applied Science \& Manufacturing, vol. 41, no. 7, pp. 806-819, 2010.

[13] H. Jiang and D. P. Kamdem, "Characterization of the surface and the interphase of PVC-copper amine-treated wood composites," Applied Surface Science, vol. 256, no. 14, pp. 4559-4563, 2010.

[14] A. K. Bledzki, A. A. Mamun, M. Lucka-Gabor, and V. S. Gutowski, "The effects of acetylation on properties of flax fibre and its polypropylene composites," Express Polymer Letters, vol. 2, no. 6, pp. 413-422, 2008.

[15] K. Suzuki, A. Sato, H. Okumura, T. Hashimoto, A. N. Nakagaito, and H. Yano, "Novel high-strength, micro fibrillated cellulosereinforced polypropylene composites using a cationic polymer as compatibilizer," Cellulose, vol. 21, no. 1, pp. 507-518, 2014.

[16] A. K. Bledzki, A. A. Mamun, A. Jaszkiewicz, and K. Erdmann, "Polypropylene composites with enzyme modified abaca fibre," Composites Science and Technology, vol. 70, no. 5, pp. 854-860, 2010.

[17] J.-M. Park, P.-G. Kim, J.-H. Jang, Z. Wang, B.-S. Hwang, and K. L. DeVries, "Interfacial evaluation and durability of modified Jute fibers/polypropylene (PP) composites using micromechanical test and acoustic emission," Composites Part B: Engineering, vol. 39, no. 6, pp. 1042-1061, 2008.

[18] M. S. Islam, S. Hamdan, M. B. Ahmad et al., "Effect of PVAco-MMA copolymer on the physical, mechanical, and thermal properties of tropical wood materials," Advances in Materials Science and Engineering, vol. 2014, Article ID 626850, 8 pages, 2014.

[19] K. K. Pandey and T. Vuorinen, "Study of kinetics of reaction of lignin model compounds with propylene oxide," Holzforschung, vol. 62, no. 2, pp. 169-175, 2008.

[20] R. G. Raj, B. V. Kokta, F. Dembele, and B. Sanschagrain, "Compounding of cellulose fibers with polypropylene: effect of fiber treatment on dispersion in the polymer matrix," Journal of Applied Polymer Science, vol. 38, no. 11, pp. 1987-1996, 1989. 
[21] L. Li and L. H. Zhao, "Preparation of natural cellulose fibers from cotton stalk and their structure and morphology," Journal of Textile Research, vol. 34, no. 2, pp. 13-17, 2013.

[22] A. Kaushik, M. Singh, and G. Verma, "Green nanocomposites based on thermoplastic starch and steam exploded cellulose nanofibrils from wheat straw," Carbohydrate Polymers, vol. 82, no. 2, pp. 337-345, 2010.

[23] M. Abdelmouleh, S. Boufi, A. B. Salah, M. N. Belgacem, and A. Gandini, "Interaction of silane coupling agents with cellulose," Langmuir, vol. 18, no. 8, pp. 3203-3208, 2002. 

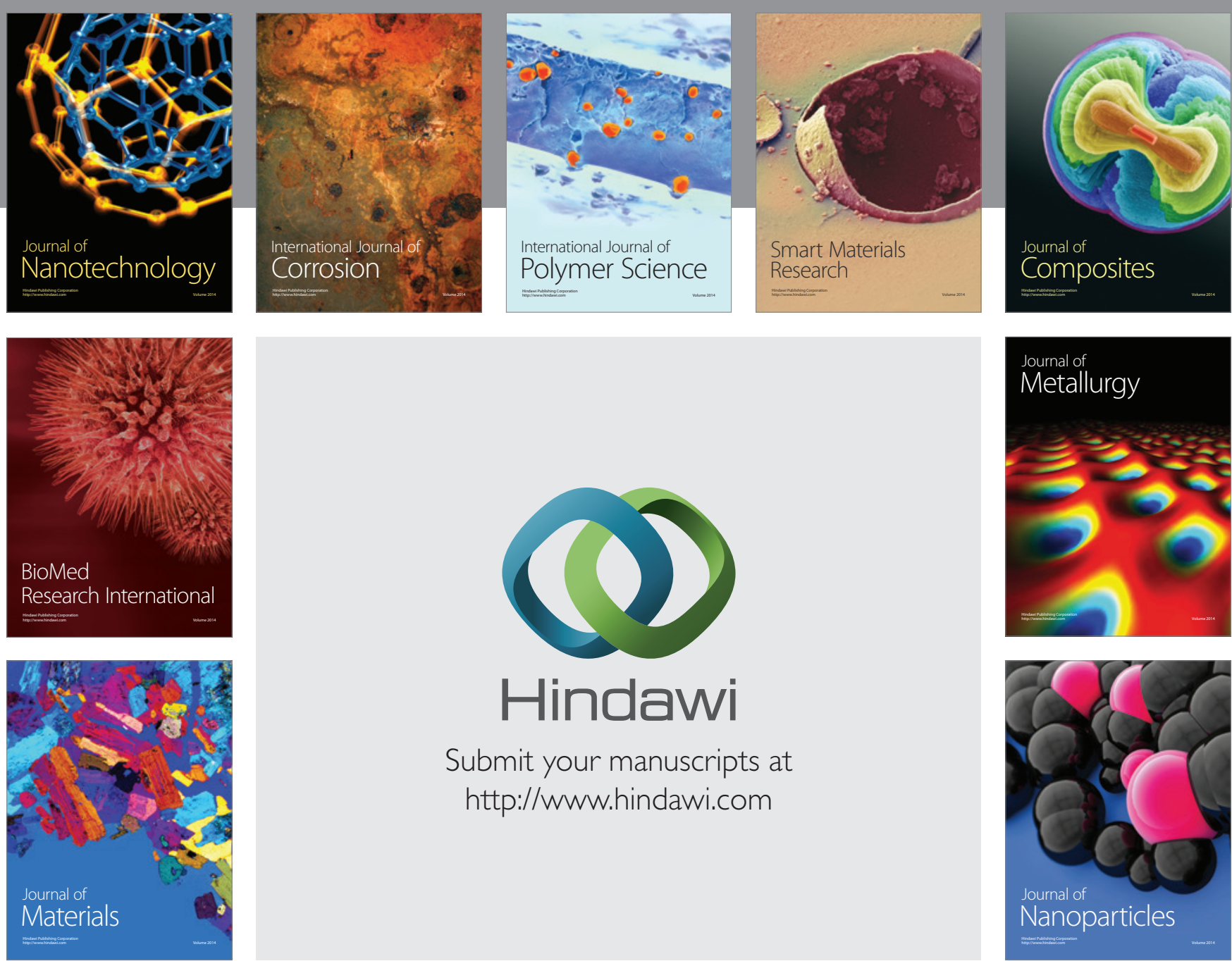

\section{Hindawi}

Submit your manuscripts at

http://www.hindawi.com

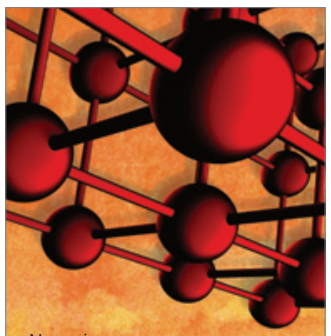

Materials Science and Engineering
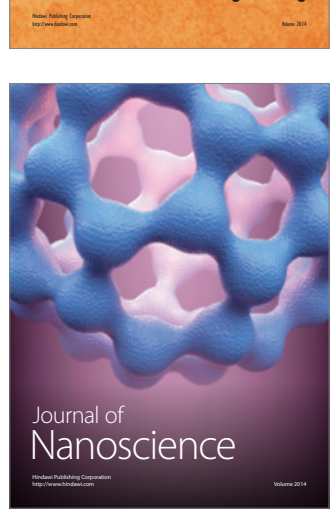
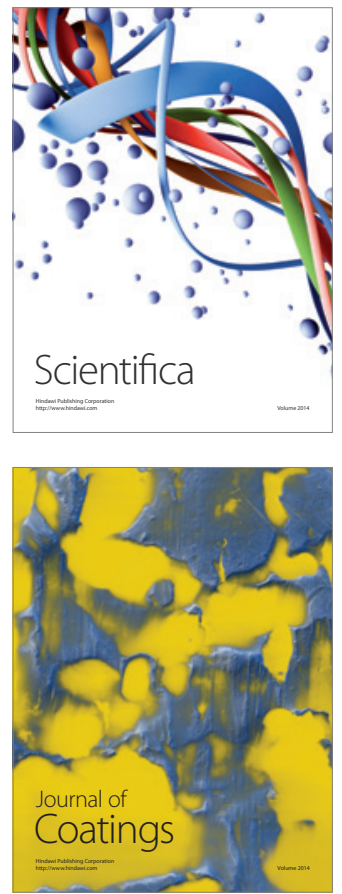
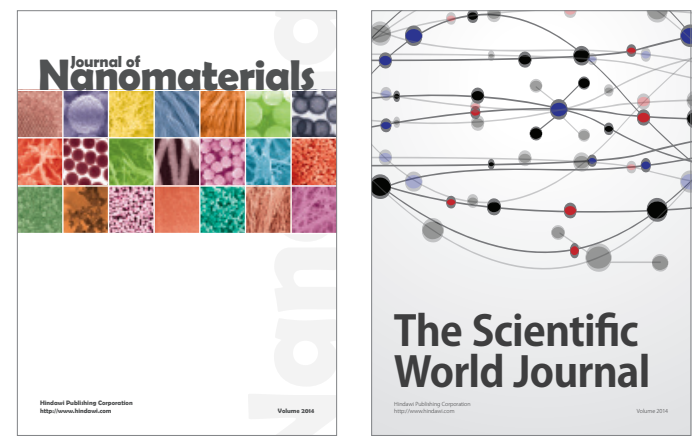

The Scientific World Journal
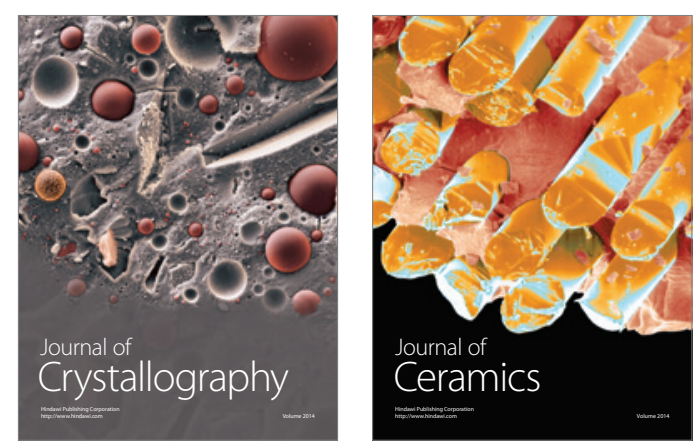
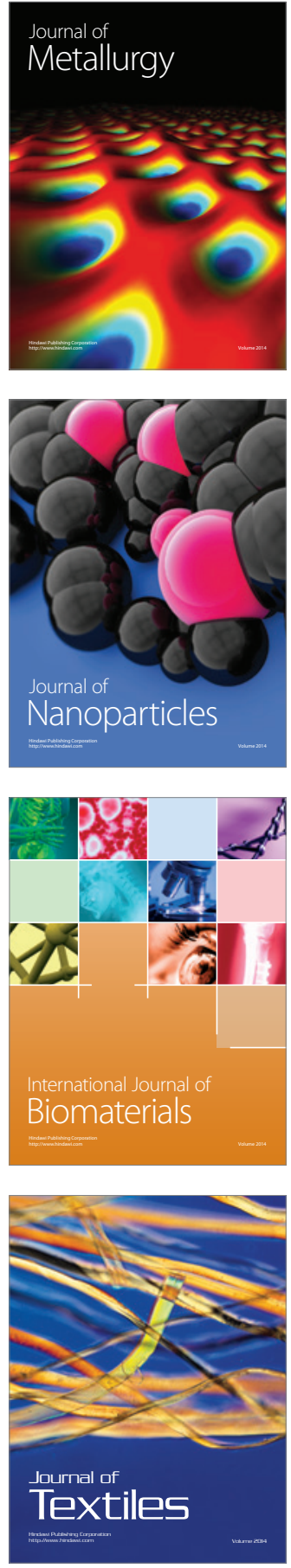